\title{
A CONSTRUÇÃO DA IDENTIDADE NEGRA VIA MOVIMENTO SOCIAL: “MARCHA DOS CABELOS CRESPOS" ENQUANTO ESTRATÉGIA DE ENFRENTAMENTO DO RACISMO
}

\author{
Deborah Dias Pereira \\ Universidade Estadual de Montes Claros (UNIMONTES)
}

Ana Paula Gilfskói Thé

Universidade Estadual de Montes Claros (UNIMONTES)

\begin{abstract}
RESUMO
Configura-se, no cenário brasileiro hodierno, uma composição de coletivos e organizações sociais que tem ganho muita força. Um desses grupos organizados refere-se ao movimento de transição capilar, termo que designa o processo de naturalização dos cabelos cacheados e crespos, visando à interrupção do uso de químicas que possibilitavam que os cabelos fossem alisados de forma definitiva. Esses movimentos alcançam maior espaço e força no meio digital, por intermédio das redes sociais, chegando também às ruas, nas formas de Marcha do Orgulho e do Empoderamento Crespo, "rolezinhos" e feiras black. Além dessas ações, em Salvador/BA, a Lei no 9.194/2017 foi sancionada, instituindo o dia 20 de Novembro como "Dia do Empoderamento Crespo", que objetiva "elevar a autoestima daqueles que por ventura se sintam inferiorizados, conscientizando-os de que todos são iguais e, portanto, são livres na forma de agir e de se apresentar perante a sociedade". A reflexão sobre a temática do cabelo perpassa pelo questionamento do eurocentrismo como padrão unificado (cultura, modos de pensar e de se vestir, parâmetro de beleza, decisões políticas e proposições históricas extremamente relevantes no Brasil), e pelo debate acerca da reificação do corpo; promovendo, assim, um aprofundamento em torno da apropriação corporal e empoderamento feminino. Nesse sentido, o presente trabalho pretende analisar criticamente a construção da identidade negra, os atravessamentos raciais que se inserem no cotidiano das vivências e os debates suscitados nos coletivos que acionam os signos capilares. Para tanto, apresenta-se uma revisão bibliográfica a respeito das categorias analíticas principais e seus respectivos desdobramentos.
\end{abstract}

Palavras-Chave: Negro. Cabelo Crespo. Movimento Social.

\section{CONSTRUCTION OF BLACK IDENTITY THROUGH SOCIAL MOVEMENT: "MARCHA DE CRESPOS" AS A STRATEGY FOR FACING RACISM}

\begin{abstract}
In the brazilian scenario today, there is a composition of collectives and social organizations that has gained much strength. One of these organized groups refers to the hair transition movement, a term that designates the process of naturalization of curly and curly hair, aiming to stop the use of chemicals that allowed the hair to be straightened permanently. These movements reach greater space and strength in the digital environment, through social networks, and also reach the streets, in the form of Pride March and Frizzy Empowerment, "rolezinhos" and black fairs. In addition to these actions, in Salvador / BA, Law No. 9,194 / 2017 was sanctioned, establishing the 20th of November as "Frizzy Empowerment Day", which aims to "raise the self-esteem of those who feel inferior, perhaps making them aware of that everyone is equal and therefore free in the way they act
\end{abstract}


and present themselves to society". The reflection on the theme of hair goes through the question of eurocentrism as a unified standard (culture, ways of thinking and dressing, parameter beauty, political decisions and historical propositions extremely relevant in Brazil), and by the debate about the reification of the body, thus promoting a deepening around the body appropriation and female empowerment. black identity, the racial crossings that are inserted in the daily life of the experiences and the debates aroused in the collectives that trigger the signs To this end, we present a bibliographical review about the main analytical categories and their respective developments.

Keywords: Black People. Frizzy Hair. Social Movement. 


\section{INTRODUÇÃO}

O movimento de "Transição Capilar" refere-se a grupos sociais que defendem o processo de naturalização dos cabelos cacheados e crespos, visando à interrupção do uso de químicas que possibilitavam que os cabelos fossem alisados de forma definitiva. Tendo seu surgimento nos Estados Unidos, a transição capilar logo angariou adeptas no Brasil, impulsionado pelas redes sociais. As referências desse processo são jovens que experienciaram a transformação dos seus cabelos numa ligação intrínseca com a construção da identidade e autoestima (MATOS, 2016).

Esses movimentos alcançam maior espaço e força na esfera digital, por meio das redes sociais (Facebook, Blogs, Twitter, Instagram, etc.), especialmente páginas que trabalham vivências de mulheres negras (tais como o Instituto da Mulher Negra (Geledés); "Blogueiras Negras"; "Encrespando Cacheando"; "Blog das Cabeludas"; "Cacheadas em Transição", dentre outros). Segundo estudos na área, o compartilhamento de experiências e narrativas pessoais nas redes funciona como ferramenta de identificação e empoderamento ${ }^{2}$. Nesse sentido, faz-se relevante o papel das mídias sociais, visto que as práticas de opressão e violências são publicizadas a partir das histórias pessoais, alargando o campo de ação dos movimentos coletivos (OLIVEIRA 2016).

Nesse contexto, o presente estudo busca analisar criticamente a construção da identidade negra, os atravessamentos raciais que se inserem no cotidiano das vivências e os debates suscitados nos coletivos que acionam os signos $^{3}$ capilares. Os processos de organização coletiva podem ser observados nas Marchas dos Cabelos Crespos, em grupos de debates em variadas redes sociais e em eventos denominados "rolezinhos".

A libertação da raiz natural ganha proporções cada vez maiores, a ponto de aparecerem nas ruas por meio de Marchas, tais como a "Marcha do Orgulho" e "Marcha do Empoderamento Crespo", presentes em diversos estados brasileiros, como São Paulo, Rio de Janeiro, Minas Gerais,

\footnotetext{
$1 \quad$ Ver https://www.geledes.org.br/; http://blogueirasnegras.org/; http://encrespandocacheando.blogspot.com/; http://blogdascabeludas.blogspot.com/; https://toemtransicao.wordpress.com/.

${ }^{2}$ Empoderamento feminino diz respeito a uma perspectiva de autonomia das mulheres nas distintas dimensões do termo, sejam culturais, sociais, políticas, econômicas, ideológicos. Segundo a Organização das Nações Unidas, o empoderamento feminino é um dos requisitos para o desenvolvimento sustentável e erradicação da pobreza. O conceito também é utilizado como categoria de análise em diversas áreas do conhecimento, sempre pautado pela transformação da vida de indivíduos, grupos e coletividades (ARAÚJO 2016).

${ }^{3}$ Signo diz respeito ao principal elemento estudado na Semiologia, podendo ser comparado com um tipo de sinal, com um objeto que emite estímulo para o mundo exterior. Desse modo, signo refere-se a um sinal especial, particular, sempre imbuído de significação (DALGALARRONDO 2008).

4 "Rolezinhos" termo inicialmente cunhado para designar a prática de eventos marcados em redes sociais que ocorriam em shopping centers das grandes cidades brasileiras, realizados basicamente por jovens oriundos da periferia. Os rolezinhos, para além da circulação de jovens da periferia nos centros como forma de lazer, estiveram associados a diversas produções culturais e propostas de intervenção no espaço urbano (como o rap, grafite, hip-hop, literatura marginal, saraus, etc.), todas elas com uma contundente crítica social envolvendo temas como violência, repressão policial, e racismo enfrentado no cotidiano (CALDEIRA, 2014; BARBOSA-PEREIRA 2016).
} 
Bahia, Goiás, Rio Grande do Sul, Paraná, Maranhão e Espírito Santo, com replicações semelhantes em outros países, a exemplo do Curl Fest, em Nova Iorque, Estados Unidos. Em Salvador/BA, a Lei $\mathrm{n}^{\circ}$ 9.194/2017 foi sancionada, instituindo o dia 20 de novembro como "Dia do Empoderamento Crespo", baseado no projeto de lei do vereador Euvaldo Jorge, que justificou o objetivo da iniciativa como forma de "elevar a autoestima daqueles que por ventura se sintam inferiorizados, conscientizando-os de que todos são iguais e, portanto, são livres na forma de agir e de se apresentar perante a sociedade" (DOM - SSA 2017).

A reflexão dessa temática perpassa pelo entendimento de dois importantes movimentos sociais: o "Movimento Negro" e o "Movimento Feminista". As contribuições advindas do "Movimento Negro" permitem que se questione o eurocentrismo como padrão unificado, com as respectivas imbricações na vida prática: cultura, modos de pensar e de se vestir, parâmetro de beleza, decisões políticas proposições históricas extremamente relevantes no Brasil, dentre outros marcadores; além de possibilitar a visibilidade da beleza multicultural, apropriação da estética afro e representatividade. Por sua vez, o "Movimento Feminista", ao promover o debate acerca dos papéis desempenhados pelas mulheres, a opressão sofrida, bem como a reificação, ou seja, objetificação do corpo feminino, até então tido como propriedade do homem, permite um estudo crítico das mensagens recebidas e naturalizadas na convivência diária, na mídia, música, literatura e outros variados ramos; promovendo, assim, avanços em torno da apropriação corporal e empoderamento feminino (MALACHIAS 2007).

Para Munanga (2009: 5) "a alienação do negro tem se realizado pela inferiorização do seu corpo antes de atingir a mente, o espírito, a história e a cultura”. De modo a estabelecer diálogo com essa ideia, a autora Bader Sawaia, em seu livro "As artimanhas da exclusão: análise psicossocial e ética da desigualdade social" (2010), sugere que ao trazer como objeto de estudo o corpo do sujeito, que até então era tomado como algo abstrato e desencarnado, permite-se que as ciências humanas possam abordar questões econômicas e políticas, inserindo as emoções e sofrimentos como demandas ético-políticas.

Como escreve a autora, refletir a exclusão, por meio da afetividade e de determinado grupo, assume caráter ético-político à medida que permite que se analise o cuidado do Estado com seus cidadãos, o descompromisso com o sofrimento humano, a noção de política permeada no cotidiano das vivências, além de pontos fundamentais a exemplo da temporalidade, economia e direitos sociais (SAWAIA 2010). 


\section{A CONSTRUÇÃO SOCIAL DA IDENTIDADE NEGRA}

A construção da identidade dos sujeitos humanos obedece sempre a diversas influências, não apenas a cultura, mas aos insumos fornecidos pela história, pelas variadas instituições, pelas religiões, experiências pessoais, bem como a memória e biologia são componentes fundamentais daquilo que se toma por construção social. Entende-se que a identidade se forma num contexto de relações de poder (CASTELLS 2008).

Conforme aborda Enriquez (2001), todo sujeito inicia sua trajetória de vida em uma sociedade que apresenta - muito antes de seu nascimento - uma cultura, manifestada de forma consciente a inconsciente. A conduta do indivíduo deve ser sempre referida à conduta dos outros para com ele, o que implica no entendimento de que o indivíduo só pode ser pensado no cerne de um social dado, no íntimo de uma cultura própria, que apresenta suas significações e representações imaginárias, norteando as ações dos variados sujeitos. Por esse motivo, o autor disserta a respeito da “anterioridade dos processos sociais", localizando o indivíduo em uma classe, um grupo, uma etnia, uma nacionalidade.

A busca pelo conhecimento acerca da questão da identidade perpassa pelo viés existencial, na medida em que os fatores cognitivos, práticos, políticos, sociais e financeiros que englobam a compreensão do nosso lugar no mundo, são suplantados pelo entendimento de se saber influenciar pelas instituições sociais e de poder. As práticas sociais de pertença a um grupo implicam em manutenção de comportamentos e ideologias, o que leva, por sua vez, a compreensão de humanidade dos próprios atores sociais (DE LA TORRE 2002 apud SILVA 2009). Nesse sentido, tratar sobre identidade implica considerar que ela apresenta um conteúdo simbólico para o indivíduo, torna-se fonte de significados para aqueles que a portam ou deixam de portar. As identidades organizam significados, promovem a ligação dos atores sociais com o objetivo de nortear as ações que estes exercem no mundo. Destarte, a identidade é algo que possibilita a continuidade do eu no tempo e no espaço, continuidade de existência humana (CASTELLS 2008).

Considerando que o mundo em que nos localizamos pode ser tomado como estritamente social, quando a realidade se torna objeto de análise, de possibilidade de conhecimento, as pessoas comuns tendem a interpretá-la mediante aprendizados que lhe foram repassados previamente, a construírem uma opinião relativamente homogênea. A predisposição genética herdada, hábitos e costumes aprendidos, reminiscências e categorias sociais se misturam para dar origem àquilo que percebemos. Logo, os conceitos que tomamos de forma naturalizada dizem respeito apenas a um elo 
em uma ampla corrente de percepções, juízos e, por fim, vidas, organizadas de maneira sequencial (MOSCOVICI, 2007).

A identidade negra, formada através das representações e atribuições de sentido dos atores sociais, engloba em sua constituição as noções de racismo estrutural, miscigenação e a falsa ideia de democracia racial presente no contexto brasileiro. Ao considerar a história do negro em nosso país, pode-se perceber que as populações de escravos e seus descendentes foram taxados por nomes depreciativos, que os diminuíam e reforçavam a exclusão social, atribuindo sentido negativo aos caracteres fenotípicos como modo de diferenciação. Ao contrário do que acontecia em outras nações, em que a ancestralidade demarcava a diferença entre o negro do não negro, no Brasil os traços físicos, o tom da pele e o tipo de cabelo denotavam a identificação de certo indivíduo como negro ou não (PEREIRA 2012).

Para Mbembe (2014), o termo "negro" é usado para se referir ao grupo de sujeitos que passaram por uma experiência histórica desoladora, que se viram emaranhados nas redes raciais da dominação. Tal fato fez com que estes sujeitos fossem transformados em espectadores da existência, visto que seus corpos e pensamentos eram definidos e controlados a partir de fora. Para além disso, o autor pontua que a condição do "negro" se liga aos processos do capitalismo à medida que legitima a exclusão e o embrutecimento acompanhado da opressão. Em suas palavras: “[...] o "negro" é, na ordem da modernidade, o único de todos os humanos cuja carne foi transformada em coisa, e o espírito, em mercadoria - a cripta viva do capital" (p. 19).

Antônio Sérgio Guimarães, reforça essa ideia ao dizer que no Brasil a cor representa mais do que puramente a cor da pele: nossa classificação racial, que compreende o branco; amarelo; preto e pardo; envolve formato de lábios e nariz, textura do cabelo, além de traços culturais. A junção de traços físicos aliados à cultura e as "boas maneiras" serviram, por muito tempo, como gradiente de embranquecimento, ideologia racial moldada a partir de teorias naturalistas presente no país séculos atrás (GUIMARÃES 2011).

\section{REPRESENTAÇÕES SOCIAIS E QUESTÕES RACIAIS}

As representações sociais que prevalecem no contexto brasileiro são embasadas em critérios hegemônicos, de modelo eurocêntrico, tendo como norma padrão o sujeito branco, heterossexual, cristão e do gênero masculino. Essa representação passa a ser tomada como regra de normalidade, como expressão da realidade social, de modo a excluir e tomar como desviante as pessoas que não se encaixam nesses parâmetros (FERNANDES; SOUZA, 2016). 
Por representações sociais entende-se o conhecimento socialmente compartilhado, que adquire característica de senso comum e pode ser notado mediante posicionamentos, opiniões e posturas de sujeitos. As representações sociais são esquemas sociocognitivos que expressam formas socialmente compartilhadas de perceber a realidade, de interagir com os outros sujeitos, denotando a compreensão histórica de dada categoria social (LEFEVRE; LEFEVRE, 2014).

Dessa forma, as representações que se criam em torno do corpo negro envolvem a percepção do "indesejável” em comparação com o corpo branco, este tido como reduto do belo, investido de atributos morais ligados à pureza, ao sagrado, referência de auto representação dos indivíduos. Rotulado pelo social, o corpo negro e suas particularidades são inscritos como marca de identidade (NOGUEIRA 1998; FERNANDES SOUZA, 2016).

A comparação dos traços negros (nariz, textura do cabelo, cor da pele, boca) em relação ao perfil branco europeu desde o período colonial serviu como assertiva de padronização e criação de um modelo de beleza e feiura que se estende hodiernamente (GOMES 2002). Consoante estudo de Djokic (2015), o entendimento do conceito de beleza pauta-se na ideia de que para ser belo é necessário ser branco. Dessa forma, o corpo negro, no intento de ser assimilado no jogo social, necessita ser embranquecido, o que leva ao uso do termo "mimetismo": orginalmente empregado na ecologia, diz respeito a um organismo que, como estratégia de sobrevivência, assume características que o confundam com indivíduos de outra espécie. No campo dos estudos raciais, o termo denota a experiência dos sujeitos negros que são forçados a praticar o mimetismo como forma de acesso a certos espaços e postos sociais. Nesse contexto, os alisamentos capilares surgiram mediante a necessidade de camuflar a presença de traços negros, permitindo, assim, a convivência no mundo dos brancos.

Para Fanon (2008: 34), uma dada população, tendo em sua história pregressa a marca da colonização, sofre de um complexo de inferioridade em relação à sua natureza: ao assimilar a linguagem e cultura da nação metropolitana sente que dessa forma conseguirá fugir de sua selva. Quanto mais se dissociar da sua mata, da sua negridão, mais civilizado será, mais próximo estará da branquitude.

Destarte, o cabelo como componente do corpo social pode ser tomado como objeto de análise, visando ao entendimento da complexa relação entre o negro e a sociedade (SANTOS 2015). Conforme aponta Sawaia (2010: 101), o sofrimento se encontra no indivíduo, contudo, esse sofrimento não tem a gênese no próprio sujeito, e sim em intersubjetividades traçadas pelo social. Ainda, segundo a autora, é possível que se faça uma análise particular das questões sociais dominantes em dado contexto histórico, por meio da escuta e do estudo do sofrimento, mesmo que esse sofrimento esteja, por vezes, naturalizado e oculto nas relações (SAWAIA 2010). 
Há tempos, a cor da pele e a textura do cabelo foram os traços mais visados para que se imprimissem noções racistas: cabelos crespos foram e ainda são tomados como "cabelo ruim", e os indivíduos de pele mais escura tidos como "negros fedidos", "feios" (MATTOS 2015). Segundo escritos da autora, a aceitação dos negros no mercado de trabalho e em ambientes extrafamiliares fora condicionada mediante normas estéticas que favorecessem aqueles que possuíssem feições mais próximas da estética branca. O usual traço de chacota ou piadas conferidas aos cabelos crespos, especialmente em idades escolares, momento que necessariamente implica socialização e convivência coletiva com diferentes, fez com que vários sujeitos fossem vítimas de preconceito e procurassem nos alisamentos capilares uma saída para a ojeriza enfrentada, uma solução que minimizasse os danos de se estar fora dos padrões socialmente aceitáveis (MATTOS, 2015). Conforme esclarece normativas de trabalho psicológico acerca das questões raciais, deve-se compreender que aos indivíduos pertencentes ao grupo negro, compreendendo pretos e pardos:

Historicamente tem sido atribuído os lugares mais desqualificados e, ao grupo racial branco, o topo da hierarquia. Esse escalonamento marca suas identidades e seus modos de vida, pois, se o topo, portanto, o ideal, está associado à população branca, ela tem maior probabilidade de constituir-se subjetivamente de forma afirmativa, já a população negra é comumente assolada por uma luta constante e, às vezes, inglória, contra o sentimento de inferioridade e, junto com ele, o de culpa por não corresponder àquele suposto ideal, bem como pelo sentimento de angústia por persistentemente passar por situações de opressão (CFP 2017:10-11).

O corpo diz sobre a nossa localização no mundo e é carregado da realidade dialética: é natural e simbólico ao mesmo tempo. O cabelo, desde o período da escravidão, caracteriza-se por definir o lugar do sujeito na estrutura social, no interior do sistema classificatório racial (GOMES 2002). Ao longo do processo de não aceitação, o negro interpôs contra sua aparência uma máscara branca, no intento de que pudesse ser branco de fato (SILVA 2016). Diante disso, os cabelos crespos foram tidos como "difíceis", "rebeldes", sendo necessário que fossem "domados", "controlados". O significante negativo aparece também nas principais formas de referenciar o cabelo crespo que, frequentemente, passam pelos termos "cabelo duro, cabelo ruim". O uso de tais expressões não é neutro, envolve, pois, emaranhada relação entre natureza e cultura. Ademais, como assegura Fanon (2008: 39), “todo idioma é um modo de pensar”. Nesse sentido, é preciso que os cabelos crespos obedeçam ao padrão de beleza existente na nossa sociedade; é necessário que sejam “controlados" (DJOKIC 2015).

Em decorrência da insatisfação com a própria imagem, pela impossibilidade de alcançar o padrão estético exigido em relação às formas físicas e capilares, muitos adolescentes e jovens negros enfrentam uma sensação de baixa autoestima, inferioridade. Essa situação ultrapassa a marca de uma experiência "comum" de insatisfação ou falta de identificação, pois é acrescida do aspecto 
racial, inseparável das questões históricas, culturais e sociais (GOMES 2002). A atitude de branqueamento, ou seja, de adoção pelo não branco de padrões, crenças e princípios associados ao universo branco objetiva ao reconhecimento de uma identidade racial positiva. São mudanças comportamentais e culturais que endossam a necessidade de pertencimento (CFP 2017).

Conforme afirma Djokic (2015), os conflitos advindos da estética podem incorrer em não aceitação de si mesmo. A modificação da aparência passa a assumir características ritualísticas, já que o sujeito modifica seus traços como modo de pertencimento, com objetivo de angariar aceitação e adequação do grupo de pares. Para Mattos (2015), “o racismo destrói subjetividades”, pois torna as pessoas escravas de recursos externos, a exemplo dos alisamentos. O valor pessoal não é intrínseco ao negro, ele deve ser conquistado por meio de parafernálias que o levem na direção do ideal branco.

De acordo com a literatura, o cabelo e o modo de penteá-lo podem servir para comunicar ou camuflar o pertencimento do indivíduo a uma dada categoria social. Mais ainda: o processo de construção identitária se faz perceptível, com todos os seus dramas e dissabores, ao notarmos que a edificação da própria aparência negra baseada na negação de seus traços fenotípicos pode expressar uma fuga, esquiva de sentimentos e vivências carregadas de afetos (DJOKIC, 2015).

Conforme assegura o CFP (2017: 30), “a identidade racial é uma identidade grupal delineada a partir de traços fenotípicos", isto é, por se referir a uma identidade de grupo, os sujeitos experienciam situações positivas ou negativas baseadas nas representações que essa identidade de grupo carrega. Mesmo que individualmente uma pessoa não se dê conta, as representações e condições materiais são relacionadas às identidades grupais.

\section{CABELO E CORPO NEGRO: O PESSOAL É TAMBÉM POLÍTICO}

Em seu estudo, Mbembe (2014) questiona se existe uma diferença de tratamento em relação ao negro em comparativo com a relação estabelecida entre o senhor e os seus criados, ou até que ponto o negro se percebe "pela" e "na" diferença. Tais questões se ancoram no entendimento de que a clivagem criada no período histórico pregresso ainda sobrevive de algum modo, os esforços feitos no sentido de hierarquizar, classificar, dividir e diferenciar ainda restam nas fendas e nas feridas da crueldade colonial. O autor, mais adiante em sua obra, reflete acerca das características presentes no estudo da identidade negra. Para ele, esta só pode ser tomada como um devir, o que significaria uma nova visão de mundo, que deixa de ser percebido como uma constante ameaça a passa a ser sentido como uma complexa rede de afinidades. Assegura existir uma "[...] identidade em devir que se alimenta simultaneamente de diferenças entre os Negros, tanto do ponto de vista 
étnico, geográfico, como linguístico, e de tradições herdeiras no encontro com Todo o Mundo" (MBEMBE 2014:167).

De acordo com Hooks (2005), nos anos de 1960 os negros que se empenhavam no trabalho de crítica e desconstrução do racismo branco apontavam a face colonizada presente nos alisamentos capilares. Esses negros, em sua maioria militantes, utilizavam o próprio cabelo natural ou com penteados afros, de modo a expressá-lo como símbolo de resistência à opressão racista, reafirmando sua condição de negro (a). Nesse contexto, o cabelo black era imbuído de significação política.

Ao tratar especificamente do racismo, considera-se que este é caracterizado como uma ampla ideologia, de proporções sistêmicas, que perpassa a economia, a política, a ética, cultura, além de estar presente na vida institucional e subjetiva das pessoas. É, pois, uma estratégia de dominação baseada na premissa de que existem raças superiores e inferiores (CFP 2017).

Falando a partir de uma perspectiva diferente, mas que toca o âmbito do corpo enquanto dispositivo de controle por parte de mecanismos diversos, as feministas de segunda onda já alertavam que "o pessoal é político". A dominação, portanto, acontece de forma oculta, sendo exercida mediante ação de variadas instituições que detêm enorme poder social (VARIKAS 1996).

Conforme assegura Oliveira (2016: 6), o uso dos cabelos naturais como ato político permite que sejam explicitadas as causas que um indivíduo defende a partir da sua estética, do uso do corpo como dispositivo não neutro, mas carregado de significações. Como ilustra uma das entrevistadas da pesquisa da autora, o posicionamento político viabilizado pelo cabelo crespo contribui para a difusão de ideias. Ao incomodar a sociedade com sua estética "diferente", gera questionamentos e favorecem debates, o que, segundo ela, "alimenta o ciclo de afirmação da própria negritude". Nesse sentido, a transição capilar assume caráter político ao possibilitar a soltura dos padrões sociais impostos. Esse processo de análise do tema ultrapassa o âmbito individual e assume caráter coletivo por entender que o cabelo crespo apresenta-se como um símbolo corporal expressivo das construções sociais e históricas, que o tinham como inferior, um elemento visível que chama à reflexão da dialética exclusão/inclusão (SAWAIA 2010; DALTRO, 2016).

\section{MODELO DE ENFRENTAMENTO: MOVIMENTOS SOCIAIS}

No contexto atual da globalização, os estudiosos têm pontuado a mudança do conflito social existente na produção para o espaço da cultura e, nesta última, as questões referentes à identidade cultural mereceriam destaque, ao passo que engendram movimentos em torno das problemáticas de raça, gênero, nacionalidade, dentre outras (GOHN 2000). 
Tendo em vista as temáticas emergentes na sociedade em relação ao racismo, alguns modelos de enfrentamento se fazem materializados. A adesão aos movimentos sociais organizados, o estudo e incorporação da cultura negra - incluindo seus marcos identitários expressos por meio de estampas, turbantes, uso de tranças, cabelo black, dentre outros - favorecem uma construção positiva e diferenciada da identidade dos sujeitos que se reconhecem enquanto negros, pertencentes a uma minoria historicamente segregada, que na atualidade demandam reconhecimento. Portanto, manter os cabelos naturais e cuidar deles permite que a ancestralidade afro seja resgatada, tratada com respeito e reverência, numa complexa gama de significantes relacionados à espiritualidade, memória e cultura negra (VIEIRA 2015).

Com a popularização da internet, diversos canais, vídeos, blogs e páginas pessoais assumiram o papel de difundir informações e insumos políticos, muitos com teor antirracista ao apoiarem a construção de laços e parcerias, despertando a sororidade ${ }^{5}$ entre seu público, de base majoritária feminina (ARRAES 2014).

A organização da sociedade civil em coletivos e Marchas dos Crespos pode ser tomada como exemplo, onde a defesa da cidadania e reunião em torno de temas de interesse público, valores, demandas por direitos distingue esse setor do Estado e do mercado. Contudo, mesmo em se tratando de um mesmo setor, a sociedade civil não se isenta de contradições e conflitos de poder, de lutas por representações sociais e ideológicas hegemônicas, além de interesses políticos antagônicos (SCHERER-WARREN 2006).

Nesse sentido, segundo Scherer-Warren, a construção de identificações, demandas semelhantes, projetos em comum, que sinalizam causas ou atores passíveis de modificação e posterior transformação social, une os sujeitos coletivos em movimentos sociais. Desse modo, movimentos sociais se referem a construção de uma identidade em torno de uma utopia ou projeto, num processo permanente de múltiplas articulações.

Na mesma perspectiva, Machado e Pérsigo (2015) asseguram que os movimentos sociais da atualidade servem-se das plataformas e mídias digitais como forma de angariar novos adeptos, facilitando a difusão de suas reivindicações. A continuidade de seus ideais com fins de viabilizar mudanças na esfera social partem da influência na opinião pública, propagando o trabalho desenvolvido. As estudiosas acrescentam que a era histórica da conectividade proporcionou aos movimentos sociais uma forma de comunicação autônoma, espaço público específico onde as características intrínsecas aos coletivos são passíveis de divulgação. O novo modelo de protesto que se forma possui como adjetivos a liberdade, imediatismo e compartilhamento instantâneo. As

\footnotetext{
${ }^{5}$ Sororidade diz respeito à "aliança feminista entre as mulheres" (p. 991), termo que engloba a noção de laços fraternos entre as mulheres, assemelhando-se àqueles laços estabelecidos entre irmãs. Envolve as dimensões éticas e políticas do feminismo contemporâneo, objetivando sua exequibilidade (GARCIA; SOUSA2015).
} 
informações, percebidas como fontes valiosas de recursos, são agora controladas e disseminadas de modo a atingir o público, corroborando na difusão das pautas. Conforme explica Matos (2016), os encontros - a exemplo das "Marchas" e "Rolezinhos Crespo" - objetivam aproximar pessoas com experiências semelhantes, de modo a trazer visibilidade e fortalecimento mútuo. Outros exemplos de eventos nessa linha são as "Feiras de Afroempreendedores", reunião de "Blogueiras Negras", "Cineblack", etc., que normalmente acontecem em conjunto com as "Marchas de Empoderamento" e "Orgulho Crespo". Ainda segundo a autora, o contexto de globalização e multiculturalismo vivenciado na atualidade favorece o surgimento de novas formas de reivindicações que se pretendem cada vai mais transversais, fato possibilitado pela atuação da sociedade civil no fortalecimento da resistência e empoderamento dos sujeitos que se encontram diante de um cotidiano de opressões e exclusão (MATOS, 2016).

Diante do exposto, cabe ampliar os estudos sobre novas formas de reidentificações, pois como afirma Scherer-Warren (2006), os movimentos sociais possuem uma realidade bastante dinâmica que, por vezes, não vem acompanhada de teorizações e estudos mais específicos. Além disso, o dinamismo de desses movimentos tende a se complexificar, dado o caráter globalizado e informatizado da sociedade.

\section{CONSIDERAÇÕES FINAIS}

Com base no conteúdo proposto no presente artigo, torna-se explícita a necessidade de prosseguimento dos estudos acerca dos temas centrais aqui resumidamente desenvolvidos. Pesquisar com mais detalhamento as Marchas de Orgulho e Empoderamento Crespo, além de entrevistas com lideranças são estratégias para que se conheça as motivações e categorias envolvidas no discurso de empoderamento proferido. Nesse sentido, faz-se necessário a continuidade desta discussão, da observação e análise acurada face às novas formas de mobilização e seus efeitos sobre o empoderamento da identidade negra.

É possível perceber, com base no levantamento bibliográfico realizado neste trabalho, que as relações entre os marcadores de classe, raça e gênero estão, muitas vezes, imbrincadas e, assim, o estudo dessas temáticas se revela bastante complexo. Entende-se que a problemática não se esgota nas categorias aqui levantadas, pois existem fatores de ordem econômica, religiosa, psíquica, identitária e social que atravessam o corpo e a vivência dos sujeitos negros e femininos. Faz-se necessário, portanto, que os estudos prossigam, na tentativa de suscitar reflexões e mudanças de paradigmas. 
Com base na discussão efetuada, nota-se que o racismo ainda persiste e permeia as práticas cotidianas, favorecendo ainda a construção da identidade e da estética negra pela ótica da inferiorização, o que faz com que o cabelo e o corpo negro lidos como "feios", "desarrumados", "inadequados" em comparativo com os padrões eurocêntricos de beleza e estética. Tais fatores necessitam ser desconstruídos, tanto nas falas cotidianas que reiteram o imaginário de que "cabelo crespo é ruim", quanto a nível das instituições e organizações sociais, como espaços escolares e corporações, que muitas vezes exigem um determinado padrão capilar ou mesmo intimam que negros e negras se desfaçam dos seus penteados black. A necessidade de mudança engloba também a construção de políticas a nível macro, a exemplo daquelas que reconhecem a relevância das Marchas do Orgulho e Empoderamento Crespo, como a Lei nº 9.194/2017, citada no início deste texto; bem como a formulação de outras garantias legais que coíbam o racismo e os discursos de ódio contra as minorias raciais.

\section{REFERÊNCIAS}

ARAÚJO. Shirlei Andreia Guedes Dantas de. 2016. O empoderamento feminino: análise da participação da mulher no mercado de trabalho e na política na religião na região metropolitana de Salvador. Revista Diálogos \& Ciências, (16-36): 87-11.

BARBOSA-PEREIRA, Alexandre. 2016. Os rolezinhos nos centros comerciais de São Paulo: juventude, medo e preconceito". Revista Latinoamericana de Ciencias Sociales, Niñez y Juventud, (14-1): 545-557.

CALDEIRA, Teresa Pires do Rio. 2014. "Qual a novidade dos rolezinhos? Espaço público, desigualdade e mudança em São Paulo”. Novos Estudos (98): 13-20.

CASTELLS, Manuel. 2010. O poder da identidade -a era da informação: economia, sociedade e cultura. São Paulo: Paz e Terra.

CONSELHO FEDERAL DE PSICOLOGIA. 2017. Relações Raciais: referências técnicas para atuação de psicólogas/os. Brasília: CFP.

DALGALARRONDO, Paulo. 2008. Psicopatologia e semiologia dos transtornos mentais. Porto Alegre: Artmed.

DALTRO, Luana Mendes. 2016. Yes, we can: a transição capilar da mulher negra na mídia tradicional e nas redes sociais. 148 f. Trabalho de Conclusão de Curso (Graduação em Comunicação Social - Relações Públicas). Faculdade de Biblioteconomia e Comunicação, Universidade Federal do Rio Grande do Sul. Porto Alegre.

DJOKIC, Aline. 2015. Colorismo: O que é, como funciona. Blogueiras Negras. Disponível em: http://blogueirasnegras.org/2015/01/27/colorismo-o-que-e-como-funciona/. Acesso em: 31 jul. 2017. 
DOM- SSA. Diário Oficial do Município de Salvador, 10 de fevereiro de 2017. Disponível em: http://www.dom.salvador.ba.gov.br/index.php?option=com_content\&view=article\&id=5445. Acesso em: 18 out. 2017.

ENRIQUEZ, Eugène. 2001. O papel do sujeito humano na dinâmica social. In: LÉVY, André (org.) et al. Psicossociologia: análise e intervenção. Belo Horizonte: Autêntica, 2001, pp. 27-44.

FANON, Frantz. 2008. Pele negra, máscaras brancas. Salvador: EDUFBA.

FERNANDES, Viviane Barboza; SOUZA, Maria Cecilia Cortez Christiano de. 2016. "Identidade Negra entre exclusão e liberdade". Revista do Instituto de Estudos Brasileiros, (63):130-120. Disponível em DOI: http://dx.doi.org/10.11606/issn.2316-901X.v0i63p103-120. Acesso em: 31 jul. 2017.

GARCIA, Dantielli Assumpção; SOUSA, Lucília Maria Abrahão. A sororidade no ciberespaço: laços feministas em militância. Estudos Linguísticos, (44-3): 991-1008. 2015

GOMES, Nilma Lino. 2002. Trajetórias escolares, corpo negro e cabelo crespo: reprodução de estereótipos ou ressignificação cultural? Revista Brasileira de Educação, (21): 40-51.

GUIMARÃES, Antônio Sérgio Alfredo. 2011. Raça, cor, cor da pele e etnia. Cadernos de Campo, (20-20): 1- 360.

HOOKS, Bell. 2005. Lia Maria dos Santos (trad.). Alisando o nosso cabelo. Revista Gazeta de Cuba - Union de escritores y artista de Cuba, tradução, 1-8p. Disponível em: $<$ https://www.geledes.org.br/alisando-o-nosso-cabelo-por-bell-hooks/\#axzz3ZBBwtIph>. Acesso em: 02 ago., 2017.

LEFEVRE, Fernando; LEVEFRE, Ana Maria Cavalcanti. Discurso do sujeito coletivo: representações sociais e intervenções comunicativas. Texto Contexto Enfermagem, (23-2): 502$507,2014$.

LERBACH, Brena Costa. 2011. Movimentos sociais: percursos práticos e conceituais. Anais do Seminário Nacional da Pós-Graduação em Ciências Sociais - UFES, (1-1). Disponível em: http://periodicos.ufes.br/SNPGCS/article/viewFile/1534/1125. Acesso em: 08 jun. 2018.

MACHADO, Anelise Lorenzon; PÉRSIGO, Patricia Milano. 2015. As novas mídias: a internet e o Facebook como plataforma de divulgação de mobilizações sociais. Temática, (11-8).

MALACHIAS, Rosangela. Cabelo bom, cabelo ruim. 2007. In: Coleção Percepções da Diferença. Negros e Brancos na Escola. São Paulo. Ministério da Educação.

MATOS, Lídia. 2016. Transição Capilar como movimento estético e político”. In: I Seminário nacional de sociologia da UFS, (1): 845-858. Anais... Disponível em: https://seer.ufs.br/index.php/snsufs/article/viewFile/6082/5095. Acesso em: 18 out. 2017.

MBEMBE, Achille. 2014. Crítica da razão negra. Lisboa: Antígona. 
MOSCOVICI, Serge. Representações sociais: investigações em psicologia social / Serge Moscovici: editado em inglês por Gerard Duveen: traduzido do inglês por Pedrinho A. Guareschi. Petrópolis, RJ: Vozes, 2007.

MUNANGA, Kabengele. 2009. Negritude: usos e sentidos. Belo Horizonte: Autêntica.

OLIVEIRA, Danielle Christina do Nascimento. 2016. Meu cabelo não é só estética, é também política: os movimentos sociais e as narrativas visuais. Revista da Associação Brasileira de Pesquisadores/as Negros/as, (8-20): 217-230.

PEREIRA, Lília Campos. 2012. "A construção da identidade da mulher negra no Brasil”. In: XV Congreso Internacional de Humanidades, Palabra y Cultura en América Latina: herencias y desafios, Santiago de Chile, 34-49 p. Disponível em: http://revistas.umce.cl/index.php/Comunicaciones/article/view/653/632.Acesso em: 31 jul. 2017.

SAWAIA, Bader. 2010. As artimanhas da exclusão: análise psicossocial e ética da desigualdade social. Petrópolis: Vozes.

SCHERER-WARREN, Ilse. 2006. Das mobilizações às redes de movimentos sociais. Sociedade e Estado (21-1): 109-130.

SILVA, Francisca Cordélia Oliveira. 2009. A construção social das identidades étnico-raciais: uma análise discursiva do racismo no Brasil.146 f. Tese (Doutorado em Linguística) - Universidade de Brasília.

SILVA, Hanna Isabel Sousa Aragão. 2016. A alienação negra em face da perda de sua identidade cultural, em O Batizado, de Cuti. Revista Somma, (2-2):135-143.

VIEIRA, Luara. 2015. A invisibilidade da estética negra: a dor do racismo sobre nossos cabelos". Geledés. Disponível em: https://www.geledes.org.br/a-invisibilidade-da-estetica-negra-a-dor-doracismo-sobre-nossos-cabelos/. Acesso em: 02 ago. 2017.

\section{AUTORAS:}

\section{Deborah Dias Pereira}

Mestranda no Programa de Pós Graduação em Desenvolvimento Social pela Universidade Estadual de Montes Claros/UNIMONTES

E-mail: deborahdias@hotmail.com.br

\section{Ana Paula Gilfskói Thé}

Professora Permanente do Programa de Pós Graduação em Desenvolvimento Social da Unimontes PPGDS

E-mail: anapgthe@gmail.com

Recebido em 25/04/2019.

Aceito em 18/09/2019. 